\title{
Vitamin D level in children with chronic kidney disease on conservative treatment - a pilot study
}

\author{
Natalia Oleksik', Katarzyna Mieleszko', Gabriela Prącik', Magdalena Kleszyk², \\ Piotr Adamczyk ${ }^{3}$, Marta Dworak ${ }^{4}$ Edyta Machura5 ${ }^{5}$ Maria Szczepańska ${ }^{5}$ \\ 'Student at Department of Pediatrics, Faculty of Medical Sciences in Zabrze, Medical University of Silesia in Katowice, Poland \\ 2Department of General Pediatrics, Independent Public Clinical Hospital No. 1, Zabrze, Poland \\ ${ }^{3}$ Department of Pediatrics, Faculty of Medical Sciences in Katowice, Medical University of Silesia in Katowice, Poland \\ ${ }^{4}$ Department of Nephrology, Independent Public Clinical Hospital No. 1, Zabrze, Poland \\ ${ }^{5}$ Chair and Department of Paediatrics, Faculty of Medical Sciences in Zabrze, Medical University of Silesia in Katowice, Poland
}

\section{ABSTRACT}

Introduction: Chronic kidney disease (CKD) is characterized by alteration of mineral metabolism of calcium and phosphorus related to phosphate retention, secondary hyperparathyroidism and impairment of vitamin D hydroxylation in the kidneys. Additionally, bone disorders can be augmented by vitamin D deficiency in the diet. Study aimed at investigation of 25-hydroxyvitamin D [25(OH)D] serum level in children with CKD treated in Pediatric Nephrology Ward, its relationship with blood pressure values, selected laboratory parameters values and evaluation of seasonal and sex related differences.

Material and methods: The study group included 28 children with CKD in stage $2-5$ (10 girls and 18 boys; mean age $9.5 \pm 5.3$ years), all of them were treated conservatively. The main cause of CKD in examined children were congenital abnormalities of the kidney and urinary tract (CAKUT). Mean estimated GFR was $40.3 \pm 23.1 \mathrm{ml} / \mathrm{min} / 1.73 \mathrm{~m}^{2}$. Seventy-five percent of patients were supplemented with vitamin D formulas. The evaluation of serum vitamin D was conducted during the routine visit in Paediatric Nephrology Ward. Serum level of 25(OH)D was measured by using an electrochemiluminescence method.

Results: In the examined group, mean height was $126 \pm 29 \mathrm{~cm}$, and $29 \%$ of children were under $3^{\text {rd }}$ percentile for height. The mean haemoglobin level was $12.4 \pm 1.9 \mathrm{~g} / \mathrm{dl}$; mean creatinine level $181.2 \pm 133.6 \mu \mathrm{mol} / \mathrm{l}$, phosphate level $1.5 \pm 0.2 \mathrm{mmol} / \mathrm{l}$; total calcium level $2.4 \pm 0.1 \mathrm{mmol} / \mathrm{l}$, mean PTH level $84.5 \pm 62.3 \mathrm{pg} / \mathrm{ml}$. Mean 25(OH)D serum level in CKD group was $38.3 \pm 14.9 \mathrm{ng} / \mathrm{ml}$ and was significantly higher than in control group $(23.3 \pm 11.3 \mathrm{ng} / \mathrm{ml} ; p<0.0001)$.

Conclusions: According to current standards of serum vitamin D level in children in Poland $61 \%$ of patients with CKD from study group had optimal vitamin D serum level without seasonal and sex related differences.

KEY WORDS:

vitamin $\mathrm{D}$, chronic kidney disease, children, short stature.

\section{INTRODUCTION}

Vitamin D deficiency is common among people living in Central Europe. The problem is exacerbated by avoiding sun exposure, using filters and insufficient vitamin D supplementation with food $[1,2]$. Furthermore, obesity, malabsorption, liver and renal diseases are known to be other risk factors for vitamin D insufficiency. In addition, medication with anticonvulsants, rifampicin, cholestyramine, highly active antiretroviral treatment (HAART)

\section{ADDRESS FOR CORRESPONDENCE:}

Prof. Maria Szczepańska, Chair and Department of Paediatrics, Faculty of Medical Sciences in Zabrze, Medical University of Silesia in Katowice, 13/15 3 Maja St., 41-800 Zabrze, Poland, ORCID: 0000-00026772-1983, e-mail: mszczepanska@szpital.zabrze.pl 
or corticosteroids may be related to declined 25-hydroxyvitamin $\mathrm{D}[25(\mathrm{OH}) \mathrm{D}]$ serum level [3].

The low concentration of $25(\mathrm{OH}) \mathrm{D}$ in the serum contributes to disturbances in the mineral and bone metabolism, which may result in rickets and fractures both in healthy children and those with chronic kidney disease (CKD) [4].

The optimal 25(OH)D serum level includes the values between 30 and $50 \mathrm{ng} / \mathrm{ml}$ and the suboptimal one between 20 and $30 \mathrm{ng} / \mathrm{ml}$. The serum concentration of $25(\mathrm{OH}) \mathrm{D}<20 \mathrm{ng} / \mathrm{ml}$ is considered to be vitamin $\mathrm{D}$ deficiency. Patients diagnosed with vitamin $\mathrm{D}$ deficiency should receive therapeutic doses of vitamin D (cholecalciferol or ergocalciferol) until they reach the optimal concentration, which is required to the effective $1,25(\mathrm{OH})_{2} \mathrm{D}$ synthesis. CKD is one of the indications to measure serum 25(OH)D concentration [1].

CKD is characterized by alteration of calcium and phosphorus mineral metabolism related to phosphate retention, secondary hyperparathyroidism and vitamin D hydroxylation disorders in kidneys. Hence, mineral and bone disorder (MBD) is frequently incident to CKD. In the paediatric population with CKD, MBD may appear through renal osteodystrophy, poor linear growth, bone deformities and fractures [5]. Fibroblast growth factor 23 (FGF23), which provides a compensative augmentation in urinary phosphorus excretion and inhibits renal 1 - $\alpha$-hydroxylase, is one of the early parameters increasing in CKD-MBD. There is also a correlation between elevated FGF23 levels and cardiovascular disease and mortality in patients with CKD as well as in general population. The lower renal 1- $\alpha$-hydroxylase activity results in a decrease in calcitriol concentration. Secondary hyperparathyroidism is attributable to CKD progression [6]. Active vitamin D analogues decrease PTH serum concentration effectively, therefore, they are widely used in advanced
CKD [7]. However, medication with metabolites or active vitamin D analogues (alfacalcidol, calcitriol, paricalcitol, doxercalciferol, oxacalcitriol, maxacalcitriol) is hormonal treatment and is not associated with serum $25(\mathrm{OH}) \mathrm{D}$ level [1].

The aim of the study was the investigation of $25(\mathrm{OH}) \mathrm{D}$ serum level in children with CKD treated in Pediatric Nephrology Ward, its relationship with blood pressure values and selected laboratory parameters values and evaluation of seasonal and sex related differences.

\section{MATERIAL AND METHODS}

The study group included children with CKD in stage $2-5$ on conservative treatment $(n=28,10$ girls and 18 boys). Estimated glomerular filtration rate (eGFR) was calculated using the Schwartz formula $\left(\mathrm{ml} / \mathrm{min} / 1.73 \mathrm{~m}^{2}\right)$ [8]. The clinical characteristics of patients is presented in Table 1. Material has been analysed retrospectively. The most common etiology of CKD was CAKUT - congenital abnormalities of the kidney and urinary tract (57\%). The other causes of CKD in the examined group included: polycystic kidney disease, glomerulonephritis, nephrotoxicity after chemotherapy of oncological malignancies and haemolytic-uremic syndrome.

Seventy-five percent $(n=21)$ of patients received vitamin D formulas at a mean daily dose of $981 \pm 575$ IU (24.5 $\pm 14.4 \mu \mathrm{g})$. Furthermore, alfacalcidol, which is vitamin D - hormone analogue, was taken by $12(42.9 \%)$ patients at a mean dose of $0.24 \pm 0.15 \mu \mathrm{g}$ per day. Ten (35.7\%) children received both preparations.

The evaluation of serum vitamin D was conducted during the routine visit in Pediatric Nephrology Ward.

Control group ( 81 children: 39 boys, 42 girls) was recruited from children, who attended the outpatient paediatric clinic for non-immunological, non-inflammatory

TABLE 1. Age, anthropometric parameters and mean arterial pressure in the examined group

\begin{tabular}{|l|c|c|c|c|c|}
\hline Parameter & $\begin{array}{c}\text { Whole CKD } \\
\text { group }\end{array}$ & Boys & Girls & $\begin{array}{c}\text { Children with } \\
\text { normal height }\end{array}$ & $\begin{array}{c}\text { Children with } \\
\text { short stature }\end{array}$ \\
\hline Age (years) & $9.6 \pm 5.3$ & $9.5 \pm 4.9$ & $9.8 \pm 6.3$ & $8.9 \pm 5.4$ & $11.2 \pm 5.2$ \\
\hline Height (cm) & $126 \pm 29$ & $128 \pm 28$ & $122 \pm 31$ & $126 \pm 32$ & $126 \pm 23$ \\
\hline Height SDS & $-1.1 \pm 1.2$ & $-0.8 \pm 1.1$ & $-1.6 \pm 1.0$ & $-0.5 \pm 0.8^{*}$ & $-2.5 \pm 0.6^{*}$ \\
\hline Body weight (kg) & $31.74 \pm 19.02$ & $33 \pm 19.3$ & $29.5 \pm 19.4$ & $32.9 \pm 20.8$ & $28.7 \pm 14.5$ \\
\hline Body weight SDS & $-0.7 \pm 1.1$ & $-0.5 \pm 1.3$ & $-0.9 \pm 0.8$ & $-0.3 \pm 1.1^{*}$ & $-1.6 \pm 0.4^{*}$ \\
\hline BMI (kg/m) & $17.8 \pm 4.3$ & $17.9 \pm 4.6$ & $17.5 \pm 3.8$ & $18.3 \pm 4.7$ & $16.6 \pm 3.0$ \\
\hline BMI SDS & $0.1 \pm 1.1$ & $0.1 \pm 1.2$ & $0.1 \pm 1.0$ & $0.2 \pm 1.2$ & $-0.2 \pm 0.9$ \\
\hline $\begin{array}{l}\text { Systolic blood } \\
\text { pressure (mm Hg) }\end{array}$ & $106.0 \pm 12.6$ & $106.1 \pm 13.0$ & $106.0 \pm 12.4$ & $105.5 \pm 12.4$ & $107.5 \pm 13.9$ \\
\hline $\begin{array}{l}\text { Diastolic blood } \\
\text { pressure (mm Hg) }\end{array}$ & $64.6 \pm 13.2$ & $65.7 \pm 13.0$ & $62.6 \pm 13.8$ & $66.5 \pm 11.9$ & $59.9 \pm 15.8$ \\
\hline MAP (mm Hg) & $78.4 \pm 12.0$ & $79.1 \pm 12.2$ & $77.1 \pm 12.2$ & $79.4 \pm 11.0$ & $75.8 \pm 14.5$ \\
\hline
\end{tabular}

Data are presented as mean $\pm S D$ (standard deviation). SDS - standard deviation score, CKD - chronic kidney disease, MAP - mean arterial pressure, BMI - body mass index, ${ }^{*} p<0.05$ 
TABLE 2. Laboratory parameters in the examined group

\begin{tabular}{|l|c|c|c|c|c|}
\hline Parameter & $\begin{array}{c}\text { Whole CKD } \\
\text { group }\end{array}$ & Boys & Girls & $\begin{array}{c}\text { Children with } \\
\text { normal height }\end{array}$ & $\begin{array}{c}\text { Children with } \\
\text { short stature }\end{array}$ \\
\hline Hemoglobin $(\mathrm{g} / \mathrm{dl})$ & $12.4 \pm 1.9$ & $12.2 \pm 1.5$ & $12.9 \pm 2.6$ & $11.9 \pm 1.4^{*}$ & $13.8 \pm 2.6^{*}$ \\
\hline Creatinine $(\mu \mathrm{mol} / \mathrm{l})$ & $181.2 \pm 133.6$ & $205.7 \pm 123.0$ & $137.1 \pm 147.2$ & $188.7 \pm 140.5$ & $162.6 \pm 121.3$ \\
\hline eGFR $\left(\mathrm{ml} / \mathrm{min} / 1.73 \mathrm{~m}^{2}\right)$ & $40.3 \pm 23.1$ & $32.7 \pm 21.4^{*}$ & $51.3 \pm 22.3^{*}$ & $39 \pm 25$ & $40.4 \pm 19.0$ \\
\hline PTH $(\mathrm{pg} / \mathrm{ml})$ & $84.5 \pm 62.3$ & $84.5 \pm 50.8$ & $84.5 \pm 85.1$ & $83.4 \pm 71.5$ & $87.3 \pm 35.3$ \\
\hline Phosphate $(\mathrm{mmol} / \mathrm{l})$ & $1.5 \pm 0.2$ & $1.6 \pm 0.3$ & $1.5 \pm 0.3$ & $1.5 \pm 0.3$ & $1.6 \pm 0.3$ \\
\hline Total calcium $(\mathrm{mmol} / \mathrm{l})$ & $2.4 \pm 0.1$ & $2.5 \pm 0.2$ & $2.5 \pm 0.2$ & $2.5 \pm 0.2$ & $2.4 \pm 0.2$ \\
\hline Vitamin D $(\mathrm{ng} / \mathrm{l})$ & $38.3 \pm 14.9$ & $37.9 \pm 14.4$ & $39.1 \pm 16.7$ & $40.0 \pm 13.9$ & $34.3 \pm 17.8$ \\
\hline Alkaline phosphatase $(\mathrm{U} / \mathrm{l})$ & $256.1 \pm 128.3$ & $265.4 \pm 128.8$ & $233.9 \pm 134.5$ & $245.8 \pm 126.6$ & $281.3 \pm 139.2$ \\
\hline Uric acid $(\mu \mathrm{mol} / \mathrm{l})$ & $388.3 \pm 120.2$ & $401.4 \pm 110.5$ & $364.7 \pm 139.0$ & $364.4 \pm 92.2$ & $448.1 \pm 164.1$ \\
\hline Total proteins $(\mathrm{g} / \mathrm{l})$ & $70.9 \pm 8.0$ & $70.3 \pm 9.6$ & $71.8 \pm 3.8$ & $70.7 \pm 5.5$ & $71.4 \pm 12.7$ \\
\hline
\end{tabular}

Data are presented as mean \pm SD. CKD - chronic kidney disease, ${ }^{*} p<0.05$

health problems and required blood tests. Twenty-four (29.6\%) among these children were on vitamin D supplementation.

Serum level of $25(\mathrm{OH}) \mathrm{D}$ was measured by using an electrochemiluminescence immunoassay (Elecsys, Roche Diagnostic, Mannheim, Germany). The detection limit was $3 \mathrm{ng} / \mathrm{ml}$.

\section{STATISTICAL ANALYSIS}

The calculations were performed using the licensed version of the Statistica 12.0 software (StatSoft Inc., USA). In statistical calculations, the level of significance was $p<0.05$. Data were shown as mean and standard deviation. For all parameters, their distribution was checked using the Shapiro-Wilk test. For comparison of variables parametric Students' $t$-test and non-parametric Mann-Whitney $U$ test were used. We performed the correlation analysis using the Pearson test or Spearman's rank correlation test - according to the distribution of the variables studied.

\section{RESULTS}

In the study group $25(\mathrm{OH}) \mathrm{D}$ serum level was $38.3 \pm 14.9 \mathrm{ng} / \mathrm{ml}$ (control group - $23.3 \pm 11.3 \mathrm{ng} / \mathrm{ml}$, $p<0.0001)$. Sixty-one percent of patients with CKD had optimal vitamin D serum level, $18 \%$ had suboptimal serum $25(\mathrm{OH}) \mathrm{D}$ concentration, $14 \%$ had high serum level of vitamin $\mathrm{D}$ and $7 \%$ of children had vitamin $\mathrm{D}$ deficiency. There was no significant difference of $25(\mathrm{OH}) \mathrm{D}$ serum level between children on supplementation (37.56 $\pm 16.4 \mathrm{ng} / \mathrm{ml})$ and children without supplementation $(40.87 \pm 10.17 \mathrm{ng} / \mathrm{ml})$ from the study group $(p=0.62)$. No statistically significant differences were found between vitamin $\mathrm{D}$ level in the sampling in summer and winter $(39.29 \pm 14.08 \mathrm{ng} / \mathrm{ml}$ vs. $37.48 \pm 16.31 \mathrm{ng} / \mathrm{ml}, p=0.76)$.

The group of children with short stature in relation to anthropometric and laboratory parameters, apart from

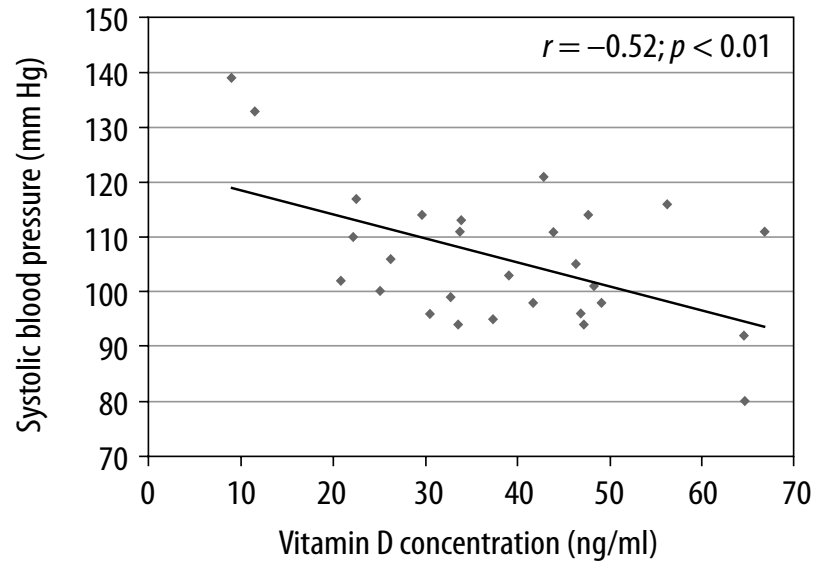

FIGURE 1. Correlation between serum vitamin D concentration and systolic blood pressure in whole group

obvious differences in height and weight, did not differ significantly from the group of children with normal height (Tables 1 and 2).

Analysis of correlation revealed a moderate negative correlation between systolic blood pressure and vitamin D serum level (Fig. 1). The inverse relationship between serum vitamin D and PTH levels has been demonstrated (Fig. 2). The association between the levels of vitamin D and creatinine also remained significant (Fig. 3).

\section{DISCUSSION}

Total serum $25(\mathrm{OH}) \mathrm{D}$ concentration was routinely monitored in the group of children with CKD during their yearly hospitalization in Pediatric Nephrology Ward. Oral cholecalciferol was implemented in the case of deficiency according to the current guidelines for vitamin D supplementation. These actions resulted in maintenance of optimal vitamin D serum level in the majority of children.

Vitamin D deficiency is more common in CKD, especially in patients with comorbid diabetes and albuminuria. However, it seems unlikely that lower vitamin D 

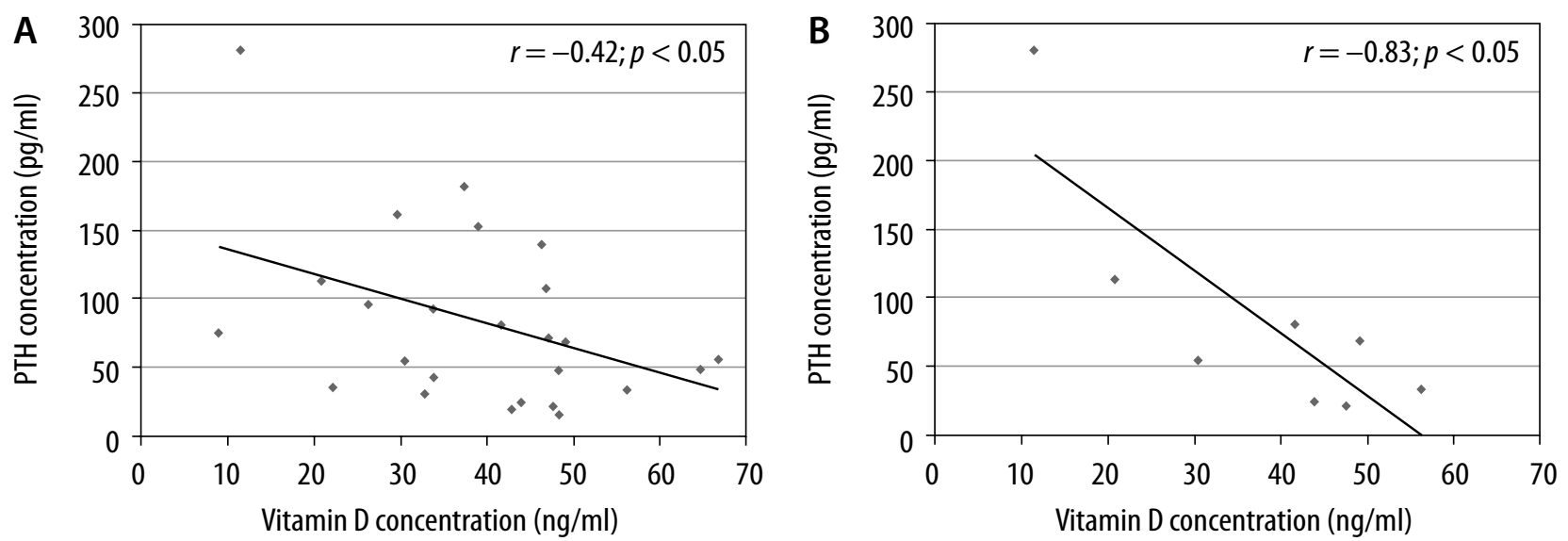

FIGURE 2. Correlation between serum vitamin D and parathyroid hormone (PTH) concentrations in whole group (A) and in girls (B)

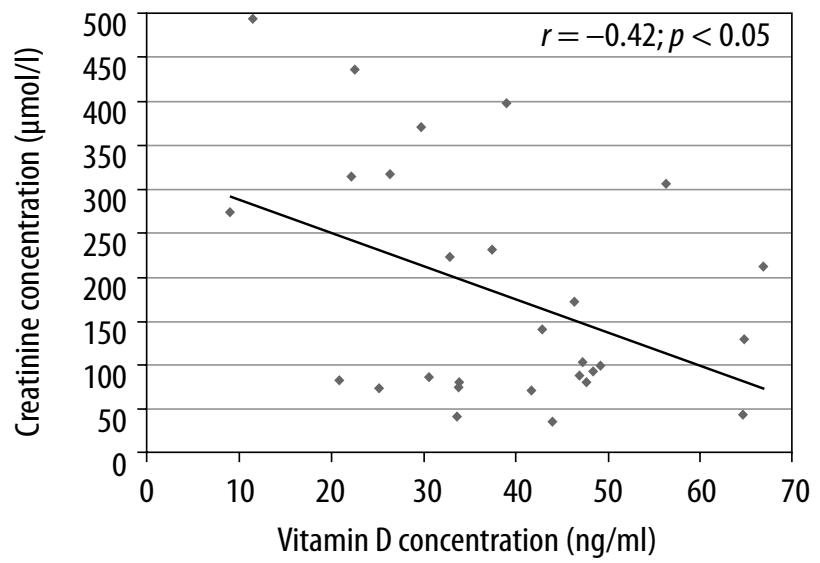

FIGURE 3. Correlation between serum vitamin D and creatinine concentrations in whole group

intake is a cause of this higher prevalence. Urinary losses or reduced gastrointestinal absorption may be related to 25(OH)D levels in CKD patients. Nevertheless, further studies are needed to evaluate this problem [9].

According to the study of Baretto et al. there was a high prevalence of vitamin D deficiency and insufficiency among 140 adults with CKD stages $2-5$. Serum $25(\mathrm{OH}) \mathrm{D}$ concentration below $15 \mathrm{ng} / \mathrm{ml}$ was found in $42 \%$ patients. In $34 \%$ subjects there was $25(\mathrm{OH}) \mathrm{D}$ serum level between 16 and $30 \mathrm{ng} / \mathrm{ml}$ [10]. In another study, which included a group of adolescent girls and elderly women living in four countries of northern Europe, vitamin D supplementation is a significant positive determinant for serum $25(\mathrm{OH}) \mathrm{D}$ concentration [11].

If indicated, vitamin D supplementation should be provided in infants and children with CKD. Targeted supplementation is preferable instead of multivitamin and multimineral one [12].

In the double-blind, randomized controlled pilot study, adult patients with CKD stages 3-4 and vitamin D insufficiency were supplemented with 50000 IU of cholecalciferol once weekly for 3 months. There was a successful treatment to correct vitamin D status and to decrease PTH levels in the study group [13]. After one year, the high dose of oral cholecalciferol (50 000 IU weekly) was safe and prevented vitamin $\mathrm{D}$ insufficiency in subjects with CKD stages 2-3. Moreover, there was an improvement of PTH serum levels, especially in patients with secondary hyperparathyroidism [14]. However, according to the Polish guidelines the therapeutic dosing of cholecalciferol or ergocalciferol in case of vitamin D deficiency, should be based on doses dependent on the 25(OH)D serum level in the risk group. Moreover age, diseases, medical therapy and body weight should be considered [15]. The high doses of vitamin D are not recommended as per "Clinical practice recommendations for native vitamin D therapy in children with chronic kidney disease stages 2-5 and on dialysis" [4].

There was a moderate negative correlation between systolic blood pressure and vitamin D serum level (Fig. 1). According to various reviews vitamin D may indirectly play a role in blood pressure modulation. However, further studies are required [16].

Our study has demonstrated an inverse relationship between serum vitamin D and PTH levels, which is consistent with other studies [9, 17-19]. According to a systematic review and meta-analysis of twenty-two studies related to vitamin $\mathrm{D}$ supplementation in CKD, there was a significant decline in PTH levels with vitamin D supplementation [20]. Additionally, the analysis of eGFR and serum PTH concentration in nine hundred and thirty people from the general Japanese population revealed that eGFR $<60 \mathrm{ml} / \mathrm{min} / 1.73 \mathrm{~m}^{2}$ is a significant risk factor for an increase in PTH levels, albeit the relationship was present only in participants with vitamin D deficiency [21].

There was also a negative relationship between the levels of vitamin $\mathrm{D}$ and creatinine. The inverse correlation between the levels of $25(\mathrm{OH}) \mathrm{D}$ and the values of creatinine was also found in the group of 333 patients with CKD stages 2-5 not undergoing dialysis treatment [22]. Vitamin D supplementation improves biochemical endpoints in patients with CKD in concordance with the results from available studies. Nevertheless, further studies are required to evaluate the impact of such improvements on clinically significant outcomes [20]. 


\section{CONCLUSIONS}

According to current standards of serum vitamin D level in children in Poland, $61 \%$ of patients with CKD from study group had optimal vitamin D serum level without seasonal and sex related differences.

\section{DISCLOSURE}

The authors declare no conflict of interest.

\section{REFERENCES}

1. Płudowski P, Karczmarewicz E, Chlebna-Sokół D, et al. Vitamin D supplementation in healthy population and risk groups of vitamin $\mathrm{D}$ deficiency - practice guidelines for Central Europe 2013. Stand Med Pediatr 2013; 10: 573-578.

2. Chwojnowska Z, Charzewska J, Wajszczyk B, et al. Trends in daily intake of calcium and vitamin D by adolescents. Probl Hig Epidemiol 2010; 91: 544-548.

3. Pearce SHS, Cheetham TD. Diagnosis and management of vitamin D deficiency. BMJ 2010; 340: b5664.

4. Shroff R, Wan M, Nagler EV, et al. Clinical practice recommendations for native vitamin $\mathrm{D}$ therapy in children with chronic kidney disease stages 2-5 and on dialysis. Nephrol Dial Transplant 2017; 32: 1098-1113.

5. Denburg MR, Kumar J, Jemielita T, et al. Fracture burden and risk factors in childhood CKD: Results from the CKiD Cohort Study. J Am Soc Nephrol 2016; 27: 543-550.

6. Kogon AJ, Harshman LA. Chronic kidney disease: Treatment of comorbidities I: (nutrition, growth, neurocognitive function, and mineral bone disease). Curr Treat Options Pediatr 2019; 5: 78-92.

7. Shroff R, Wan M, Nagler EV, et al. Clinical practice recommendations for treatment with active vitamin $\mathrm{D}$ analogues in children with chronic kidney disease stages 2-5 and on dialysis. Nephrol Dial Transplant 2017; 32: 1114-1127.

8. Schwartz GJ, Munoz A, Schneider MF, et al. New equations to estimate GFR in children with CKD. J Am Soc Nephrol 2009; 21: 1-9.

9. Mehrotra R, Kermah D, Budoff M, et al. Hypovitaminosis D in chronic kidney disease. Clin J Am Soc Nephrol 2008; 3: 1144-1151.

10. Baretto DV, Baretto FC, Liabeuf S, et al. Vitamin D affects survival independently of vascular calcification in chronic kidney disease. Clin J Am Soc Nephrol 2009; 4: 1128-1135.

11. Andersen R, Molgaard C, Skovgaard LT, et al. Teenage girls and elderly women living in northern Europe have low winter vitamin D status. Eur J Clin Nutr 2005; 59: 533-541.

12. Joyce $\mathrm{T}$, Rasmussen $\mathrm{P}$, Melhem $\mathrm{N}$, et al. Vitamin and trace element concentrations in infants and children with chronic kidney disease. Pediatr Nephrol 2020; 35: 1463-1470.

13. Chandra P, Binongo JNG, Ziegler TR, et al. Cholecalciferol (vitamin D3) therapy and vitamin $\mathrm{D}$ insufficiency in patient with chronic kidney disease: a randomized controlled pilot study. Endocr Pract 2008; 14: 10-17.

14. Alvarez JA, Law J, Coakley KE, et al. High-dose cholecalciferol reduces parathyroid hormone in patients with early chronic kidney disease: a pilot, randomized, double-blind, placebo-controlled trial. Am J Clin Nutr 2012; 96: 672-679.

15. Rusińska A, Płudowski P, Walczak M, et al. Vitamin D supplementation guidelines for general population and groups at risk of vitamin D deficiency in Poland - Recommendations of the Polish society of Pediatric Endocrinology and Diabetes and the Expert Panel with Participation of National Specialist Consultants and
Representatives of Scientific Societies - 2018 Update. Front Endocrinol 2018; 9: 246.

16. Mehta V, Agarwal S. Does vitamin D deficiency lead to hypertension? Cureus 2017; 9: e1038.

17. Levin A, Bakris GL, Molitch M, et al. Prevalence of abnormal serum vitamin D, PTH, calcium, and phosphorus in patients with chronic kidney disease: Results of the study to evaluate early kidney disease. Kidney Int 2007; 71: 31-38.

18. LaClair RE, Hellman RN, Karp SL, et al. Prevalence of calcidiol deficiency in CKD: a cross-sectional study across latitudes in the United States. Am J Kidney Dis 2005; 45: 1026-1033.

19. Napiórkowska L, Budlewski T, Jakubas-Kwiatkowska W, et al. Prevalence of low serum vitamin D concentration in an urban population of elderly women in Poland. Pol Arch Med Wewn 2009; 119: 699-703.

20. Kandula P, Dobre M, Schold JD, et al. Vitamin D supplementation in chronic kidney disease: a systematic review and meta-analysis of observational studies and randomized controlled trials. Clin J Am Soc Nephrol 2011; 6: 50-62.

21. Daimon M, Fujita T, Murabayashi M, et al. Exacerbation of hyperparathyroidism, secondary to a reduction in kidney function, in individuals with vitamin D deficiency. Front Med 2020; 7: 221.

22. Restrepo Valencia CA, Aguirre Arango JV. Vitamin D (25(OH)D) in patients with chronic kidney disease stages 2-5. Colomb Med (Cali) 2016; 47: 160-166. 